\title{
МОДЕЛИРОВАНИЕ КУПОЛЬНОЙ ЧАСТИ АРХИТЕКТУРНОГО ОБЪЕКТА В 3D MAX
}

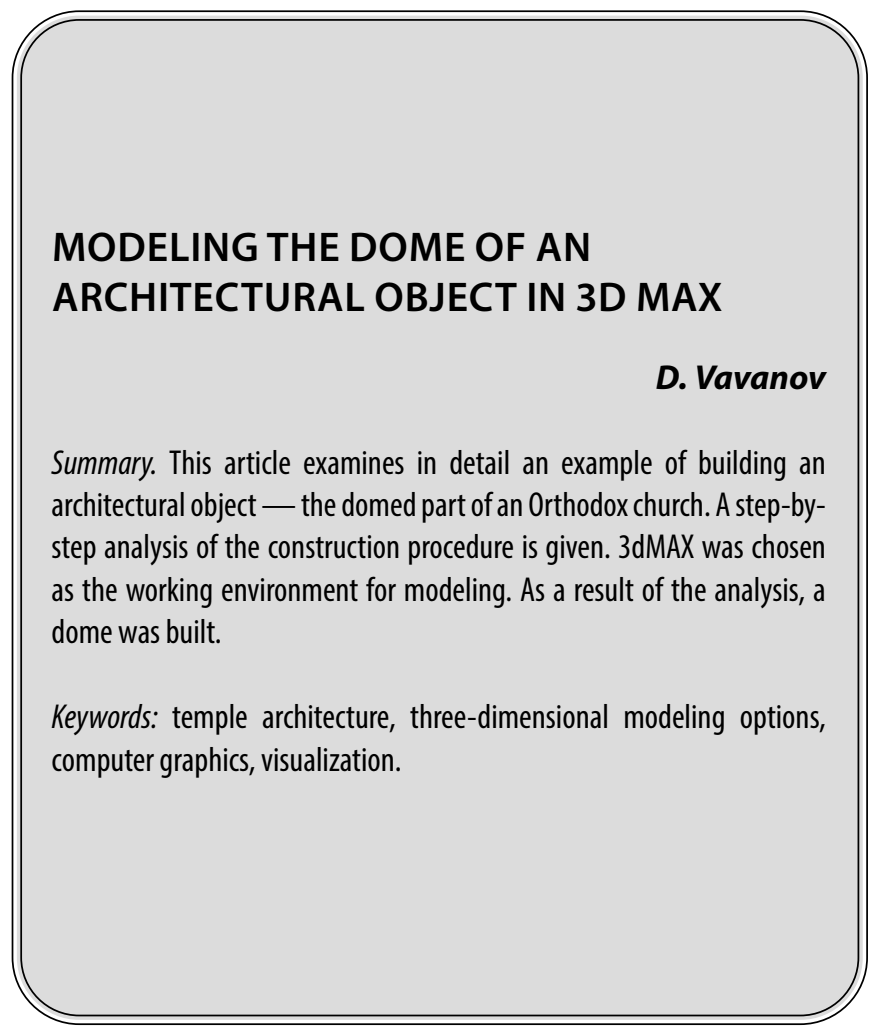

B современных компьютерных технологиях существуют несколько программ, позволящих моделировать объекты архитектуры - это 3dMAX, AutoCAD, ArchiCAD, Revit и другие. Среди этих программ 3dMAX выгодно отличается универсальностью построений. В этой программе достаточно легко можно смоделировать сложные архитектурные сооружения, и получать не только статические, но и динамические изображения (видеоролики).

В данной статье рассмотрим моделирование купольной части храма.

Необходимо отметить, что любой объект в этой программе можно смоделировать различными способами (непосредственное использование подходящих примитивов; использование плоских и пространственных сплайнов с последующей обработкой; использование логических операций).

На первом этапе построим постамент, представляющий собой квадратную плиту. Для этого используем примитив BOX (см. рис. 1).

\author{
Ваванов Дмитрий Алексеевич \\ Преподаватель, Московский Государственный \\ Строительный Университет, г. Москва \\ kohinor51@yandex.ru
}

Аннотация. В данной статье подробно разбирается пример построения архитектурного объекта — купольной части православного храма. Приводится поэтапный анализ процедуры построения. В качестве рабочей среды моделирования выбран 3dMAX. В результате проведенного анализа построен купол.

Ключевые слова: храмовая архитектура, варианты трехмерного моделирования, компьютерная графика, визуализация.

На следующем этапе необходимо скорректировать форму этой плиты, и для этого можно воспользоваться логической операцией вычитания. Необходимо создать два горизонтальных цилиндра одинакового радиуса, оси которых пересекаются под прямым углом, и образующие которых параллельны боковым граням плиты.(см. рис. 2).

Создадим новый объект в категории Compound посредством применения булевской операции. Для этого вначале нужно выделить созданный объект (плиту), установить тип операции - Subtraction, и в качестве операндов указыавать цилиндры (вначале первый, а затем второй). В результате применения этой операции должен появиться следующий объект (см. рис 3)

Дальше произведем моделирование барабана. В геометрическом отношении он представляет собой расположенную на невысоком цилиндре полую трубу с симметрично расположенными прорезями для окон. Поэтому вначале построим невысокий цилиндр, восользовавшись соответствующим примитивом, отцентрируем его в плане по построенной ранее плите, и затем выровняем 


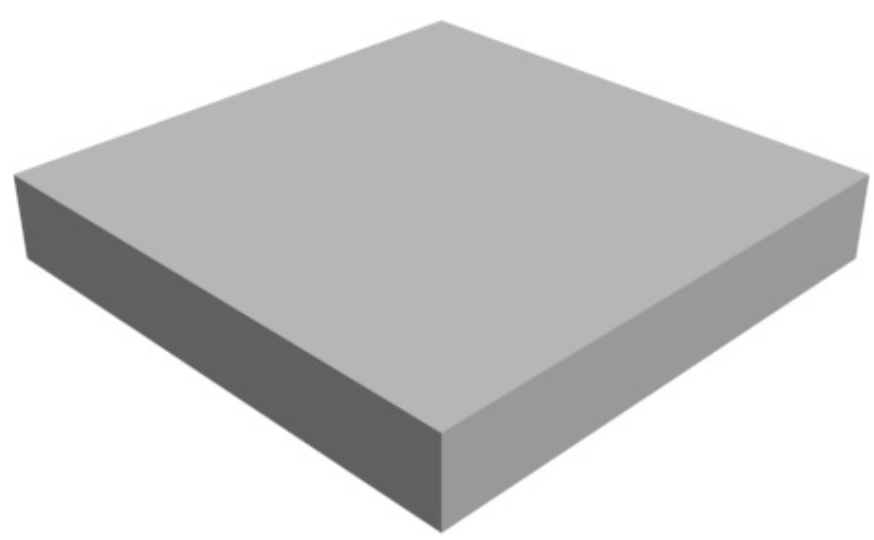

Рис. 1. Начальный этап построения купольной части храма.

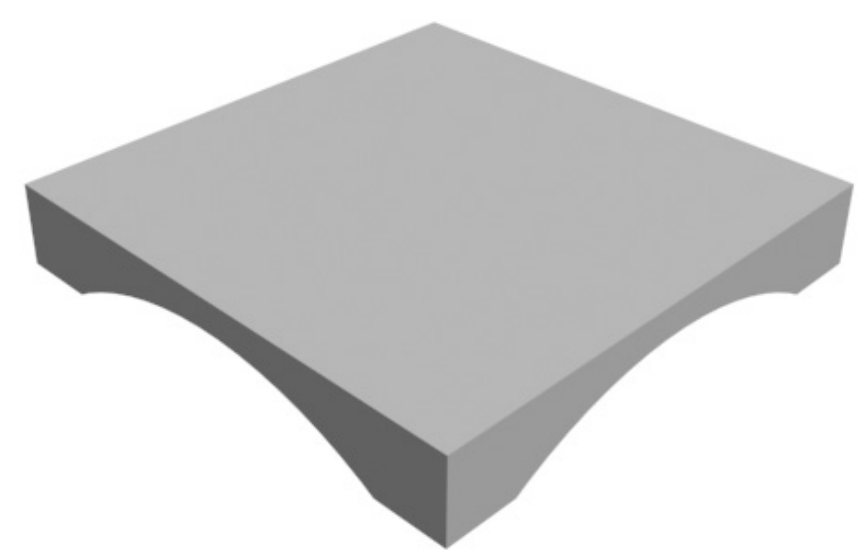

Рис. 3. Результат применения булевской операции вычитания из одной плиты двух цилиндров.

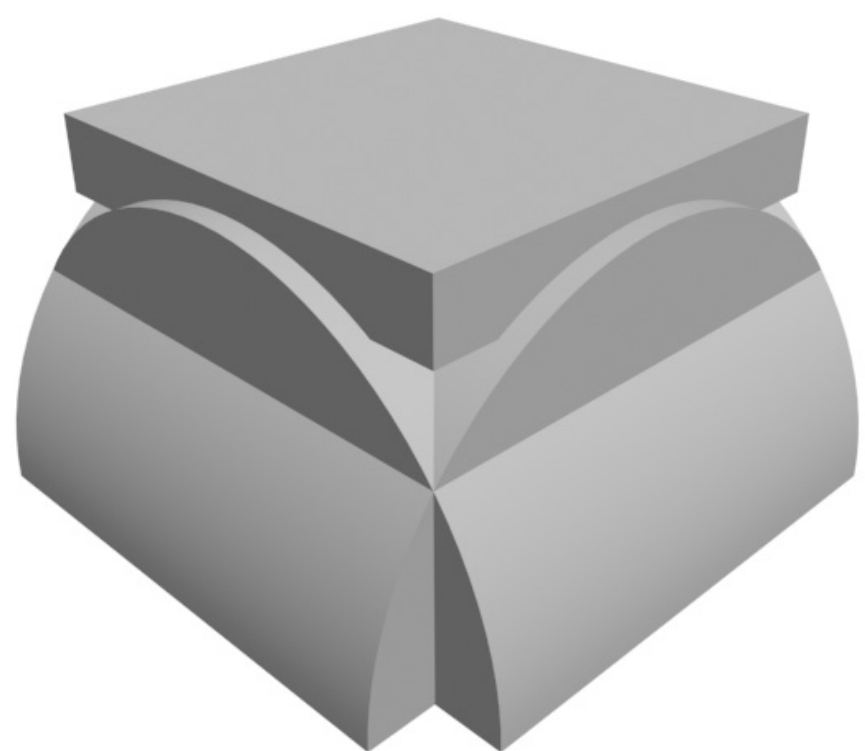

Рис. 2. Примитивы, служащие операндами в булевской операции вычитания.

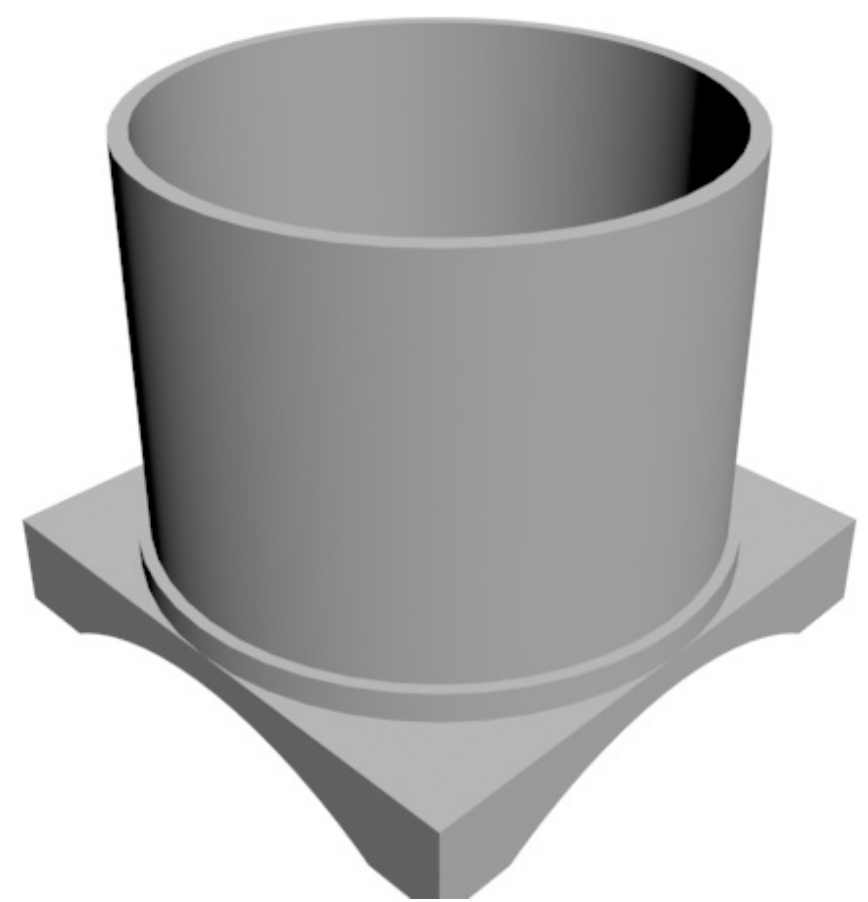

Рис. 4. Начальный этап построения барабана.

линдра. В результате должно получиться следующее (см. рис. 4).

Затем необходимо прорезать окна. Для формирования профиля одного окна начертим замкнутый сплайн нужной формы, и выдавим этот сплайн, используя модификатор Extrude, при этом установим величину вы- 


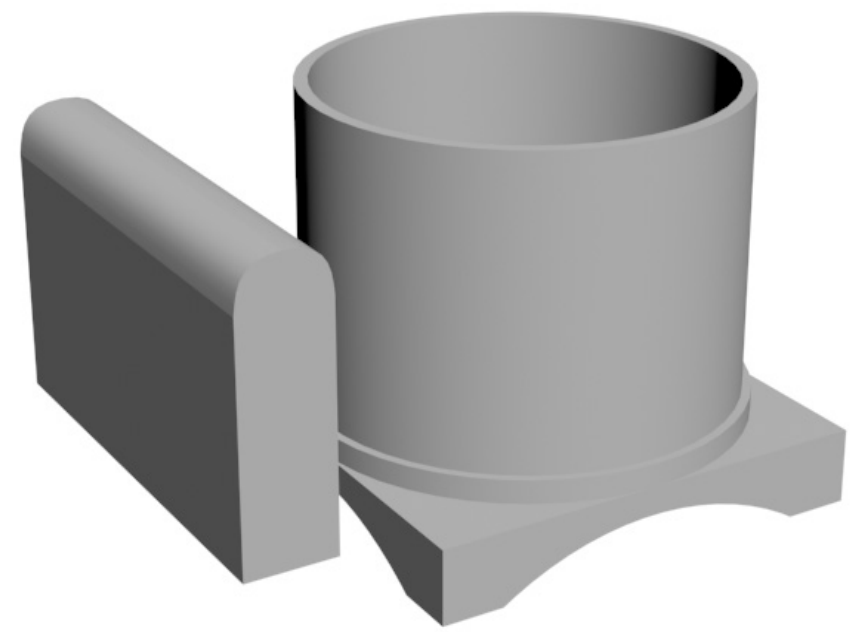

Рис. 5. Формирование объекта, «пробивающего» окна в барабане.

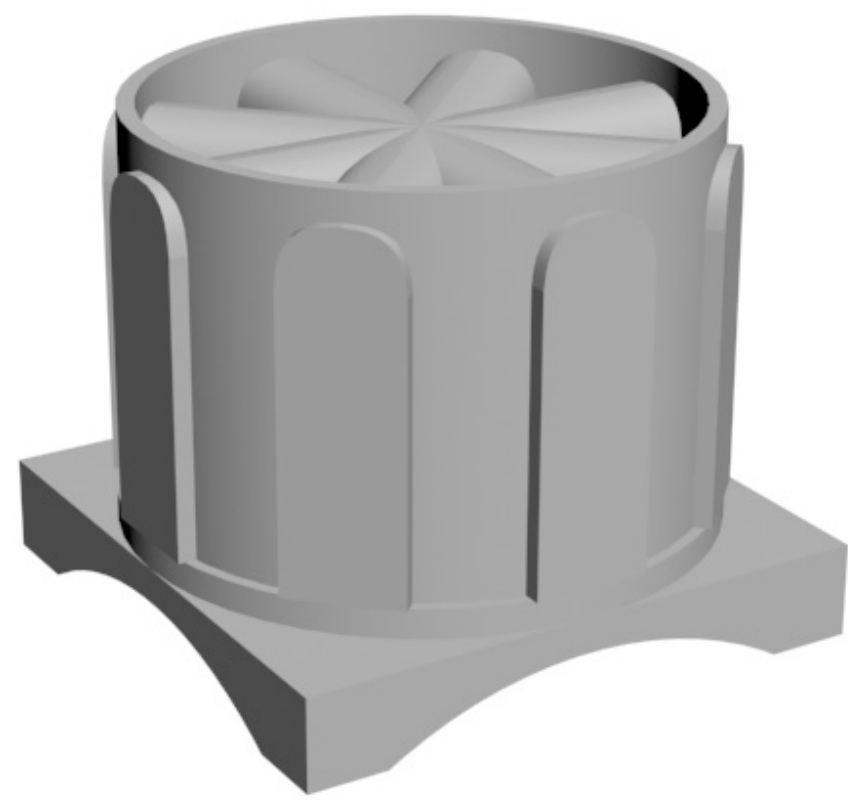

Рис. 7. Результат выполнения команды Array для пробойника

давливания, превышающую внешний диаметр трубы. Это будущий «пробойник», посредством которого будут прорезаться окна в барабане. (см. рис. 5).

Затем надо правильно позиционировать только что созданный объект относительно трубы-барабана. Отцентрируем его в плане относительно трубы, а по высоте в данной конкретной версии архитектурного объекта

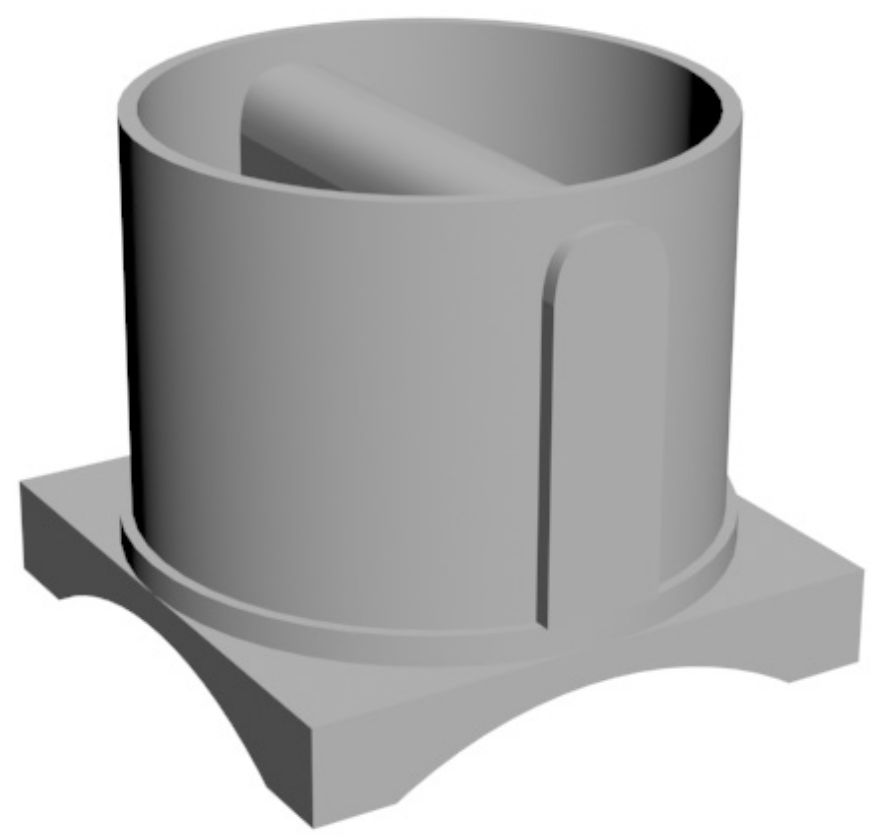

Рис. 6. Установленный пробойник окон

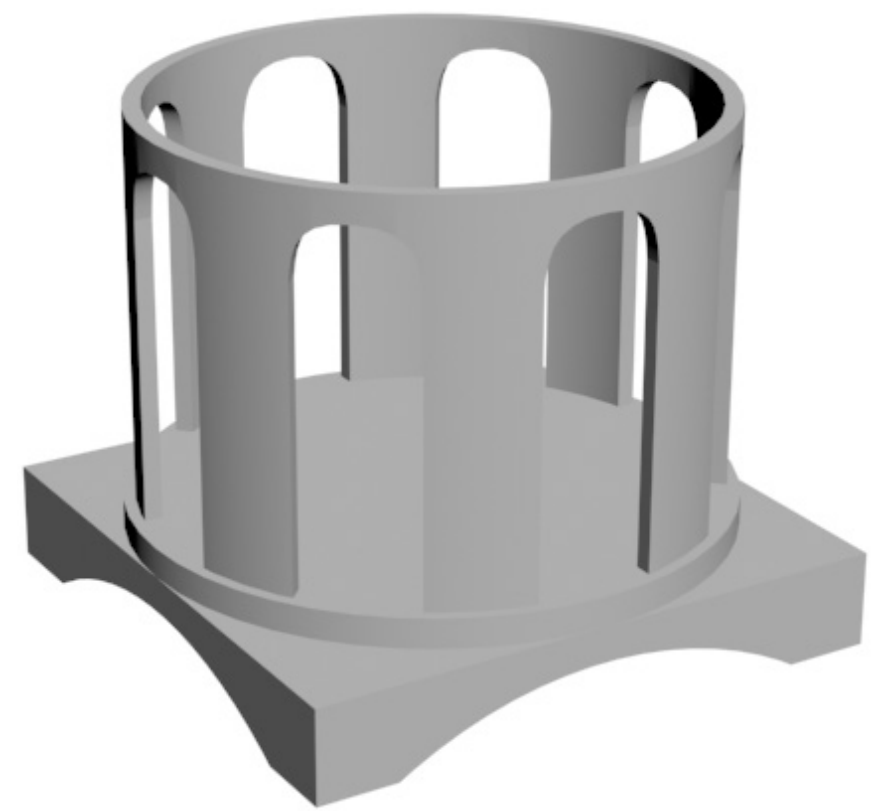

Рис. 8. Этап построения купольной части храма. Барабан с пробитыми отверстиями под окна.

установим его точно на верхнюю грань цилиндра барабана (см. рис. 6).

Необходимо содать несколько копий этого «пробойника». Для этого необходимо воспользоваться командой Array, создающей круговой массив копий элементов. Но прежде выполнения этой команды нужно необходимо отцентрировать точку Gizmo (точка приложения 
модификаторов). Во вкладке Hierarchy вкладки Modify устанавливаем Gizmo в нужную точку. Затем объект готов к применению команды Array.

Поскольку каждый пробойник порождает сразу 2 окна, высекаемых на противоположных участках барабана, то для формирования 8 окон понадобится 4 пробойника.

Выполним команду Array, создавая круговой массив элементов, при этом угол между соседними элементами установим 45 градусов. Результат показан на рис. 7.

Затем необходимо пробить окна. Для этого устновим курсор на барабане, а затем во вкладке Create выберем тип создаваемого объекта - Compound, конкретизируем тип сложности - Boolean, и, наконец, укажем тип логической операции - Subtracion. Затем последовательно будем указывать курмором мыши на конкретные экземпляры пробойников, в результате чего кадый раз пробойники будут исчезать, но при этом появляться пары окон. (см. рис. 8).

\section{$\mathrm{BuBO} \triangle$}

В заключение можно сделать вывод о том, что 3dMAX позволяет с минимальными затратами временных ресурсов добиться реалистическогоизображения геометрии любых сложных архитектурных объектов. В отличие от системы AutoCAD, ориентированной прежде всего на машиностроительные чертежи, все построения можно проводить с меньшим количеством уточняющих запросов. Это дает некоторые потери в точности построения, но зато при этом увеличивается скорость работы проектировщика -архитектора и дизайнера. Вдобавок 3dMAX позволяет эффективно работать с материалами, цветом и различными текстурами, позволяя использоватьфотографии в качестве карт цвета, прозрачности и выпуклости, что существенно повышает реалистичность итогового изображения.

\section{ЛИТЕРАТУРА}

1. Миловская 0. С. 3ds Мax 2018 и 2019. Дизайн интерьеров и архитектуры. Дизайн интерьеров и архитектуры. СПб. 2019. 178с.

2. Горелик. А. 3ds Max 2018. СПб. 2018. 528c.

3. Антонова Н. Е., Вятчанина Т. Н., Рыцарев К. В., Щенков А. С. Архитектура русского православного храма. Памятники исторической мысли. М. 2013. 528с.

4. Кеслер М. Ю. Православные храмы. Том 2. Православные храмы и комплексы. Пособие по проектированию и строительству. 2003. 223с.

5. Шубенкова М. Ю. Компьютерное моделирование как средство архитектурно-исторического анализа. https://marhi.ru/AMIT/2008/2kvart08/Shubenkova/ Shubenkova02_AMIT_3_paper.pdfC.9 